\title{
Liposome Co-sedimentation and Co-flotation Assays to Study
} Lipid-Protein Interactions

\section{Senju, Yosuke}

Humana press

2021

Senju , Y , Lappalainen , P \& Zhao , H 2021 , Liposome Co-sedimentation and Co-flotation

Assays to Study Lipid-Protein Interactions . in RJ Botelho (ed.), Phosphoinositides .

Methods in Molecular Biology , vol. 2251, Humana press , pp. 195-204 . https://doi.org/10.1007/978-1-0716-1142-5

http://hdl.handle.net/10138/340528

https://doi.org/10.1007/978-1-0716-1142-5_14

acceptedVersion

Downloaded from Helda, University of Helsinki institutional repository.

This is an electronic reprint of the original article.

This reprint may differ from the original in pagination and typographic detail.

Please cite the original version. 


\title{
Liposome co-sedimentation and co-flotation assays to study lipid-protein interactions
}

\author{
Yosuke Senju $^{1 *}$, Pekka Lappalainen ${ }^{2}$ and Hongxia $\mathrm{Zhao}^{3,4,5 *}$
}

${ }^{1}$ Research Institute for Interdisciplinary Science (RIIS), Okayama University, 3-1-1 Tsushima-naka, Kita-ku, Okayama 700-8530 Japan

${ }^{2}$ Institute of Biotechnology, University of Helsinki, FI-00014 Helsinki, Finland

${ }^{3}$ Faculty of Biological and Environmental Sciences, University of Helsinki, FI-00014 Helsinki, Finland

${ }^{4}$ School of life Sciences, Guangxi Normal University

${ }^{5}$ Key Laboratory of Stem Cell and Biopharmaceutical Technology, Guangxi Univesities

Running Head: In vitro assays to study lipid-protein interactions

*Corresponding authors:

Dr. Hongxia Zhao,

Faculty of Biological and Environmental Sciences, University of Helsinki,

Finland

Viikinkaari 9, 00790, Helsinki

Email: hongxia.zhao@helsinki.fi

Dr. Yosuke Senju

Research Institute for Interdisciplinary Science (RIIS), Okayama University

3-1-1 Tsushima-naka, Kita-ku, Okayama 700-8530, Japan

Email: yosuke.senju@okayama-u.ac.jp 


\begin{abstract}
A large proportion of proteins are expected to interact with cellular membranes to carry out their physiological functions in processes such as membrane transport, morphogenesis, cytoskeletal organization, and signal transduction. The recruitment of proteins at the membrane-cytoplasm interface and their activities are precisely regulated by phosphoinositides, which are negatively charged phospholipids found on the cytoplasmic leaflet of cellular membranes and play critical roles in membrane homeostasis and cellular signaling. Thus, it is important to reveal which proteins interact with phosphoinositides, and to elucidate the underlying mechanisms. Here, we present two standard in vitro methods, liposome co-sedimentation and co-flotation assays, to study lipid-protein interactions. Liposomes can mimic various biological membranes in these assays, because their lipid compositions and concentrations can be varied. Thus, in addition to mechanisms of lipid-protein interactions, these methods provide information on the possible specificities of proteins towards certain lipids like specific phosphoinositide species, and can hence shed light on the roles of membrane interactions on the functions of membrane-associated proteins.
\end{abstract}

\title{
Key words
}

Phosphoinositides, Liposome, Lipid-protein interactions, Phospholipids, Binding mode 


\section{Introduction}

Many proteins are proposed to play their physiological functions through binding to cellular membranes. The plasma and intracellular membranes have different lipid compositions that enables localization of specific proteins to distinct subcellular compartments [1,2]. For example, one of the phosphoinositides, phosphatidylinositol 4,5-bisphosphate $\left[\mathrm{PI}(4,5) \mathrm{P}_{2}\right]$, is abundant at the plasma membrane, where it regulates the functions of several actin-binding proteins that control the dynamics of the actin cytoskeleton $[3,4]$. Interactions of proteins with $\mathrm{PI}(4,5) \mathrm{P}_{2}$ may affect their association with binding-partners, or induce conformational changes in proteins. Such lipid-induced conformational changes can for example release the auto-inhibited protein structures as demonstrated in the case of actin-regulatory proteins N-WASP and Ezrin/Radixin/Moesin [ERM] [5-7]. Furthermore, certain $\mathrm{PI}(4,5) \mathrm{P}_{2}$-binding proteins, including the Bin/Amphiphysin/Rvs (BAR) domain proteins, can reciprocally regulate membrane properties such as fluidity, curvature, tension, and lateral diffusion of lipids [8-10]. Therefore, it is crucial to understand the lipid-binding affinities, specificities and mechanisms of proteins.

Here, we present two basic in vitro methods to study lipid-protein interactions. One is a liposome co-sedimentation assay, which is a simple method to identify membrane-binding proteins through sedimentation of the protein-bound liposomes to separate them from the unbound proteins using ultracentrifugation. Membrane-binding proteins or protein domains can be identified by this approach, and their membrane binding affinities as well as possible lipid-specificities can be uncovered by modifying the concentrations and lipid-compositions of the vesicles. In addition, membrane binding modes (electrostatic vs. hydrophobic, cooperative vs. non-cooperative) of proteins can be determined by altering the salt concentration in the reaction buffer and the molar ratio of phosphoinositides. The other method is liposome co-flotation assay, which can be applied to study protein-lipid interactions in cases where the protein of interest forms large oligomers or aggregates during the co-sedimentation assay [11]. In the liposome co-flotation assay, the membrane-binding proteins float with liposomes in a sucrose gradient during centrifugation. Taken together, in vitro liposome co-sedimentation and co-flotation assays are useful tools to identify membrane-binding proteins, and to provide mechanistic insights into these interactions.

\section{Materials}

\subsection{Phospholipids}

1-Palmitoyl-2-oleoyl-glycero-3-phosphocholine (POPC) is dissolved in chloroform at $4.39 \mathrm{mM}$. 1Palmitoyl-2-oleoyl-sn-glycero-3-phosphoethanolamine (POPE) is dissolved in chloroform at 4.64 mM. 1-Palmitoyl-2-oleoyl-sn-glycero-3-phospho-L-serine (POPS) is dissolved in chloroform at 4 
mM. PI(4,5) $\mathrm{P}_{2}$ is dissolved in chloroform:methanol:water (20:9:1) at $0.57 \mathrm{mM}$. Rhodamine DHPE is dissolved in chloroform at $0.25 \mathrm{mM}$. The phospholipids should be purged with an inert gas (for example $\mathrm{N}_{2}$ ) to prevent oxidation and stored in glass tubes at $-20{ }^{\circ} \mathrm{C}$ (see Note 1 ).

\subsection{Stock Solutions}

1. Lysis buffer: $20 \mathrm{mM}$ Tris- $\mathrm{HCl}$ (pH 7.5), $150 \mathrm{mM}$ sodium chloride (NaCl), 0.1\% Triton X-100, 1 $\mathrm{mM}$ ethylenediaminetetraacetic acid (EDTA), $1 \mathrm{mM}$ phenylmethanesulfonyl fluoride (PMSF), and 1 mM dithiothreitol (DTT).

2. Cleavage buffer: $50 \mathrm{mM}$ Tris- $\mathrm{HCl}$ (pH 7.5), $150 \mathrm{mM} \mathrm{NaCl}, 1 \mathrm{mM}$ EDTA, and $1 \mathrm{mM}$ DTT.

3. Binding buffer (HEPES Buffered Saline, HBS): $20 \mathrm{mM}$ HEPES (pH 7.5) and $100 \mathrm{mM} \mathrm{NaCl}$ (see Notes 2 and 3).

4. HBS containing $0.3 \mathrm{M}, 60 \%$, and $25 \%$ (w/v) sucrose.

5. Laemmli sample buffer ( $4 \times$ concentration): $8 \%$ SDS, $40 \%$ glycerol, $20 \%$ 2-mercaptoethanol, $0.02 \%$ bromophenol blue, and $0.25 \mathrm{M}$ Tris $\mathrm{HCl}, \mathrm{pH} 6.8$.

\subsection{Reagents and Equipment for protein expression and purification}

1. Glutathione S-Transferase (GST) or His-tagged vector.

2. BL21(DE3) Competent E. coli.

3. Glutathione agarose.

4. LB medium.

5. Ampicillin $(100 \mathrm{mg} / \mathrm{mL})$ in sterile distilled/deionized water stored at $-20{ }^{\circ} \mathrm{C}$.

6. Isopropyl $\beta$-D-1-thiogalactopyranoside (IPTG) $(0.1 \mathrm{M})$ in sterile distilled/deionized water stored at $-20{ }^{\circ} \mathrm{C}$.

7. Sonicator.

8. Protease.

9. Chromatography.

10. Gel filtration column.

11. Centrifugal protein concentrators.

12. Ni-NTA agarose.

\subsection{Reagents and Equipment for co-sedimentation and co-flotation assays}

1. Methanol.

2. Chloroform.

3. Glass tubes. 


\section{Glass syringes.}

5. Nitrogen gas.

6. Pressured gas blowing concentrator.

7. Vacuum concentrator.

8. Vortex mixer..

9. Tabletop ultracentrifuge

10. Fixed-angle rotor $(20 \times 0.2 \mathrm{~mL})$.

11. Thickwall polypropylene tube $(230 \mu \mathrm{L})$.

12. Swinging-bucket rotor $(4 \times 2.2 \mathrm{~mL})$.

13. Thinwall polypropylene tube $(2.2 \mathrm{~mL})$.

14. Microvolume UV-Vis Spectrophotometer.

15. Microcentrifuge tubes, $1.5 \mathrm{~mL}$.

16. Heat block.

17. Pre-cast or "home-made" gels for sodium dodecyl sulphate-polyacrylamide gel electrophoresis (SDS-PAGE).

18. Coomassie Brilliant Blue (CBB) $[0.25 \%(\mathrm{w} / \mathrm{v})]$ in $40 \%(\mathrm{v} / \mathrm{v})$ methanol and $7 \%(\mathrm{v} / \mathrm{v})$ acetic acid.

19. Gel imaging analysis software.

20. Fluorescence spectrometer.

\section{Methods}

\subsection{Protein expression and purification (1 L culture)}

1. Prepare a construct by sub-cloning a gene encoding a protein of interest into a GST-tagged vector (see Note 4).

2. Transform the construct into BL21 (DE3) competent cells (see Note 5).

3. Pick a single colony and inoculate it into $10 \mathrm{~mL} \mathrm{LB}$ medium containing $100 \mu \mathrm{g} / \mathrm{mL}$ ampicillin and incubate at $37{ }^{\circ} \mathrm{C}$ with shaking at $200 \mathrm{rpm}$ overnight. Then, add the entire volume to $1000 \mathrm{~mL} \mathrm{LB}$ medium containing $100 \mu \mathrm{g} / \mathrm{mL}$ ampicillin.

4. Incubate the culture medium at $37^{\circ} \mathrm{C}$ with shaking until the optical density at 600 (OD600) reaches 0.6. Then, induce protein expression by adding IPTG to a final concentration of $0.2 \mathrm{mM}$ (see Note 6).

5. After overnight induction at $16{ }^{\circ} \mathrm{C}$, harvest the cells by centrifugation at $3,000 \times g$ for 10 min at $4{ }^{\circ} \mathrm{C}$ (see Note 7).

6. Resuspend the cells in ice-cold $40 \mathrm{~mL}$ lysis buffer and lyse the cells by sonication $(10 \mathrm{~s} \times 6)$ on ice (see Note 8). 
7. Centrifuge the lysed cells at $12,000 \times g$ for $20 \mathrm{~min}$ at $4{ }^{\circ} \mathrm{C}$ and collect the supernatant.

8. Equilibrate $500 \mu \mathrm{L}$ (bed volume) glutathione agarose by washing twice with lysis buffer.

9. Add the equilibrated glutathione agarose to the cell lysate and incubate for $1 \mathrm{~h}$ at $4{ }^{\circ} \mathrm{C}$ with gentle rotation.

10. Wash the protein-bound glutathione agarose four times with ice-cold lysis buffer.

11. Wash the protein-bound glutathione agarose once with ice-cold cleavage buffer.

12. Add protease to ice-cold cleavage buffer, then add this to the protein-bound glutathione agarose, and incubate at $4{ }^{\circ} \mathrm{C}$ overnight with rotation (see Note 9).

13. Centrifuge the solution at $500 \times g$ for $5 \mathrm{~min}$ at $4{ }^{\circ} \mathrm{C}$ to pellet the glutathione agarose and carefully transfer the supernatant (eluted fraction) to a microcentrifuge tube.

14. Equilibrate a gel filtration column with the buffer $(20 \mathrm{mM}$ Tris- $\mathrm{HCl}$ and $150 \mathrm{mM} \mathrm{NaCl}, \mathrm{pH} 7.5$, $1 \mathrm{mM}$ PMSF, and $1 \mathrm{mM}$ DTT) (see Notes 10 and 11).

15. Load the eluate onto the gel filtration column with an FPLC system. Confirm the purity of the protein in the peak fractions (the fraction volume could be for example $0.5-3 \mathrm{~mL}$ depending on various columns and proteins) by SDS-PAGE followed by CBB staining.

16. Pool the pure proteins and concentrate with centrifugal protein concentrators. The final concentration of proteins can be $100 \mu \mathrm{M}$ in the buffer $(20 \mathrm{mM}$ Tris- $\mathrm{HCl}$ and $150 \mathrm{mM} \mathrm{NaCl}, \mathrm{pH} 7.5$, $1 \mathrm{mM}$ PMSF, and $1 \mathrm{mM}$ DTT). Aliquot the proteins, freeze in liquid nitrogen, and store them at $-80{ }^{\circ} \mathrm{C}$.

\subsection{Preparation of multilamellar vesicles (MLVs)}

1. In a fume hood, add each lipid from lipid stocks in organic solvent (e.g., PC, PE, PS, and PI(4,5) $\mathrm{P}_{2}$ ) including fluorescently-labeled lipids into glass tubes using glass syringes according to the desired lipid composition (see Note 12). For example, the lipid composition is POPC:POPE:POPS:PI(4,5)P 2 :rhodamine DHPE (50:19.5:20:10:0.5, mol/mol), and the concentration is $1 \mathrm{mM}$.

2. Evaporate solvents such as chloroform and methanol under a stream of nitrogen gas in the fumehood, and then remove the remaining organic solvent with a vacuum concentrator for $2 \mathrm{~h}$.

3. Add binding buffer to obtain a final lipid concentration of $1 \mathrm{mM}$, for example. Hydrate lipids for at least $1 \mathrm{~h}$ with vortexing at room temperature (see Note 13) to generate MLVs.

\subsection{Liposome co-sedimentation assay (see Fig. 1)}

1. Ultracentrifuge protein solutions at $436,000 \times g$ for $30 \mathrm{~min}$ at $4{ }^{\circ} \mathrm{C}$ using a pre-cooled fixed-angle centrifuge rotor to get rid of protein aggregates, and carefully collect the supernatant. 
2. Measure the protein concentrations again with a microvolume UV-Vis spectrophotometer.

3. Pipette binding buffer so that the total volume will be $50 \mu \mathrm{L}$ into the ultracentrifugation tubes. The buffer volume is $50 \mu \mathrm{L}$ total volume minus the volumes of protein and liposomes.

4. Pipette proteins into the ultracentrifugation tubes at a final concentration of $1 \mu \mathrm{M}$, for example (see Notes 14 and 15).

5. Pipette liposomes into the ultracentrifugation tubes at a final concentration of $0.5 \mathrm{mM}$, for example. A negative control (a buffer without any liposomes) is important to include in all assays.

6. Mix the solutions by pipetting gently to avoid disturbing the liposomes and incubate for $30 \mathrm{~min}$ at room temperature.

7. Place the tubes in the fixed-angle rotor ensuring that the tubes are balanced properly.

8. Ultracentrifuge at $436,000 \times g$ for $30 \mathrm{~min}$ at $20^{\circ} \mathrm{C}$.

9. Immediately after the ultracentrifugation, carefully remove the tubes from the rotor to avoid disturbing the pellets.

10. Transfer the supernatant to new microcentrifuge tubes (see Notes 16).

11. Resuspend the pellets in $50 \mu \mathrm{L}$ binding buffer and transfer to new microcentrifuge tubes. (see Notes 17 and 18)

12. Add $4 \times$ Laemmli sample buffer to the supernatant and pellets.

13. Incubate samples on a heat block at $95{ }^{\circ} \mathrm{C}$ for $5 \mathrm{~min}$.

14. Perform SDS-PAGE followed by CBB staining.

15. Image SDS-PAGE gels and quantify the intensity of each band with a gel imaging analysis software (see Notes 19).

16. The binding affinities of the proteins of interest are estimated by calculating the band intensities using the equation: pellet/(supernatant + pellet), when the assay is performed by keeping the protein concentration constant and varying the concentration of lipids.

\subsection{Liposome co-flotation assay (see Fig. 2)}

1. Ultracentrifuge protein solutions at $436,000 \times g$ for $30 \mathrm{~min}$ at $4{ }^{\circ} \mathrm{C}$ using a pre-cooled fixed-angle rotor to get rid of protein aggregates.

2. Prepare MLVs according to the method described in Subheading 3.2 by hydrating with the HBS containing $0.3 \mathrm{M}$ sucrose.

3. Add protein to $150 \mu \mathrm{L}$ of MLV solution (e.g., $1 \mathrm{mM}$ ) in the ultracentrifugation tubes at a final concentration of $1 \mu \mathrm{M}$, for example. Gently mix and incubate for $10 \mathrm{~min}$ at room temperature.

4. Add $100 \mu \mathrm{L}$ of HBS containing $60 \%$ sucrose and gently mix the solution. This will provide a sucrose concentration of $30 \%$. 
5. Carefully overlay (drop by drop against the wall of the tube) $200 \mu \mathrm{L}$ HBS containing $25 \%$ sucrose on top of the above solution.

6. Carefully overlay (drop by drop against the wall of the tube) $200 \mu \mathrm{L}$ of HBS on top of the above solution.

7. Centrifuge samples at $259,000 \times g$ for $30 \mathrm{~min}$ using a swinging-bucket rotor.

8. Carefully collect $100 \mu \mathrm{L}$ of each fraction from top to bottom into microcentrifuge tubes.

9. Confirm the lipid fractions with the fluorescence spectrometer. Take a few microliters $(2 \mu \mathrm{L}$, for example) from each fraction and dilute with HBS to a total volume of $100 \mu \mathrm{L}$ (in cuvettes). Set the excitation and emission wavelengths at 560 and $580 \mathrm{~nm}$, respectively, and measure the rhodamine fluorescence in each fraction.

10. Add $4 \times$ Laemmli sample buffer to each fraction.

11. Incubate samples on a heat block at $95{ }^{\circ} \mathrm{C}$ for $5 \mathrm{~min}$.

12. Carry out SDS-PAGE followed by CBB staining (see Notes 18).

13. Image SDS-PAGE gels and quantify the intensities of each band with a gel imaging analysis software.

\section{Notes}

1. The glassware, but not plastic tubes, should be used to handle the organic solvents such as methanol and chloroform.

2. Salt concentrations of the binding buffer can be varied to study whether the membrane-binding modes of proteins depend on the electrostatic interactions or not. When the membrane-binding of the proteins depends on the electrostatic interactions, the affinities of proteins to the membranes decrease with the increase in salt concentration in the binding buffer. This will be useful to study whether proteins bind to negatively-charged head groups of phosphoinositides. Special attention should be paid to make sure that the protein of interest does not aggregate (solution becomes cloudy) when the salt concentration in the binding buffer decreases.

3. The $\mathrm{pH}$ of the binding buffer can be varied to examine whether the membrane-binding of the proteins is $\mathrm{pH}$ dependent that can affect the subcellular localizations of membrane-binding proteins.

4. His-tagged proteins can be used as well using Ni-NTA agarose resin if the GST-tag is too large to express proteins of interest.

5. If the proteins of interest are difficult to express, other bacterial strains such as Rosetta (DE3) can be used.

6. Optimize the IPTG concentration to improve protein expressions.

7. The time and temperature of expression can be optimized. 
8. If the proteins tend to be insoluble, optimize buffer conditions such as salt concentrations and $\mathrm{pH}$.

9. Proteases can remove GST-tags from fusion proteins.

10. Choose a gel filtration column that is appropriate for the molecular weight of the proteins under investigation.

11. Alternatively, a cation or anion exchange column (depending on the theoretical $\mathrm{pI}$ of the proteins of interest) can be used to improve protein purity.

12. Various lipid compositions, including phosphatidylinositol monophosphate [PI(3)P, PI(4)P, $\mathrm{PI}(5) \mathrm{P}]$, diphosphate $\left[\mathrm{PI}(3,4) \mathrm{P}_{2}, \quad \mathrm{PI}(3,5) \mathrm{P}_{2}, \quad \mathrm{PI}(4,5) \mathrm{P}_{2}\right]$, triphosphate $\left[\mathrm{PI}(3,4,5) \mathrm{P}_{3}\right]$, different phosphoinositide concentrations, can be used by mimicking the lipid compositions of distinct cellular membranes to elucidate the subcellular localizations of proteins [12].

13. The temperature for lipid hydration should be higher than the lipid phase transition temperature of the desired lipid composition, which can be measured, for example, by differential scanning calorimetry.

14. Recombinant proteins purified from E. coli should be as pure as possible, and the GST- or Histags should be removed to avoid nonspecific binding or interference in membrane-binding of proteins. 15. The protein concentrations can be varied; however, special attention should be paid to avoid over saturation of membrane binding.

16. Special attention should be paid not to disturb or pipette the pellets when collecting the supernatant. Gel-loading pipet tips can be used.

17. Proteins tend to be absorbed onto tube surfaces. Low adsorption microtubes that reduce the adsorption of proteins can be used.

18. The addition of fluorescently-labeled lipids such as $0.5 \%(\mathrm{~mol} / \mathrm{mol})$ rhodamine DHPE allows the visualization of liposome fractions in the tubes.

19. This can be done with western blotting if affinity/recovery is weaker and if antibodies are available. 


\section{Figures}

a

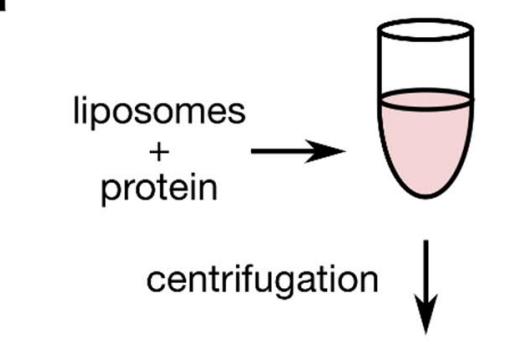

b

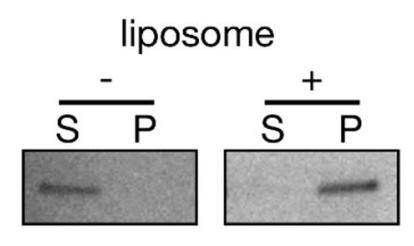

Moesin FERM

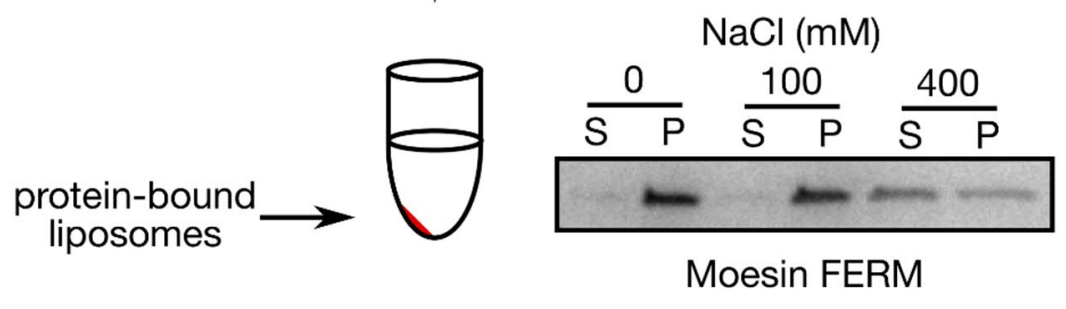

Fig. 1 Liposome co-sedimentation assay to study protein-phosphoinositide interactions. (a) Schematic representation of liposome co-sedimentation assay. (b) (Upper) Images of CBB-stained SDS-PAGE gels after the liposome co-sedimentation assay of Moesin FERM domain. S and P indicate the supernatant fraction, and the pellet fraction containing the protein-bound liposomes, respectively. The lipid composition was POPC:POPE:POPS:PI(4,5) $\mathrm{P}_{2}$ :rhodamine DHPE (50:19.5:20:10:0.5, mol/mol). The concentration of Moesin FERM domain was $1 \mu \mathrm{M}$, and that of liposomes was $1 \mathrm{mM}$. (Lower) Salt sensitivity of the interaction of Moesin FERM domain with liposomes. The $\mathrm{NaCl}$ concentration was varied at $0 \mathrm{mM}, 100 \mathrm{mM}$, and $400 \mathrm{mM}$. The concentration of Moesin FERM domain was $1 \mu \mathrm{M}$, and that of liposomes was $1 \mathrm{mM}$ [12]. 
a

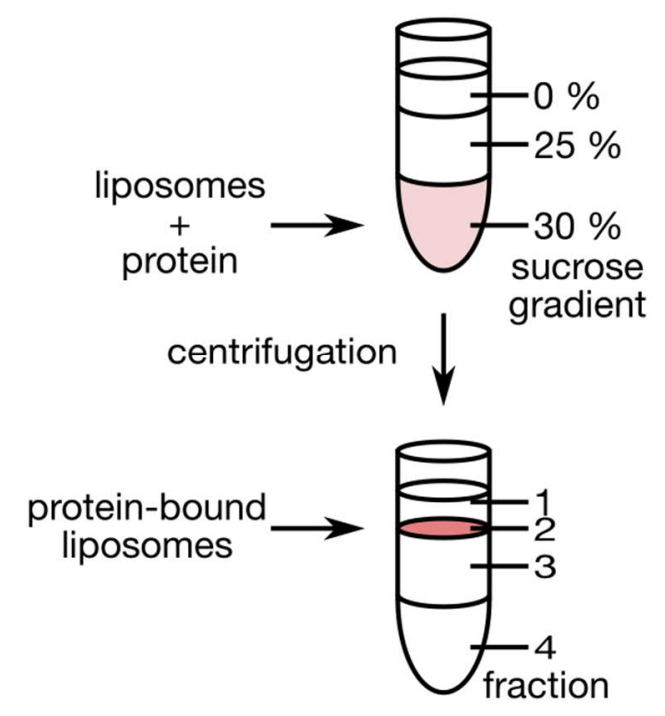

b

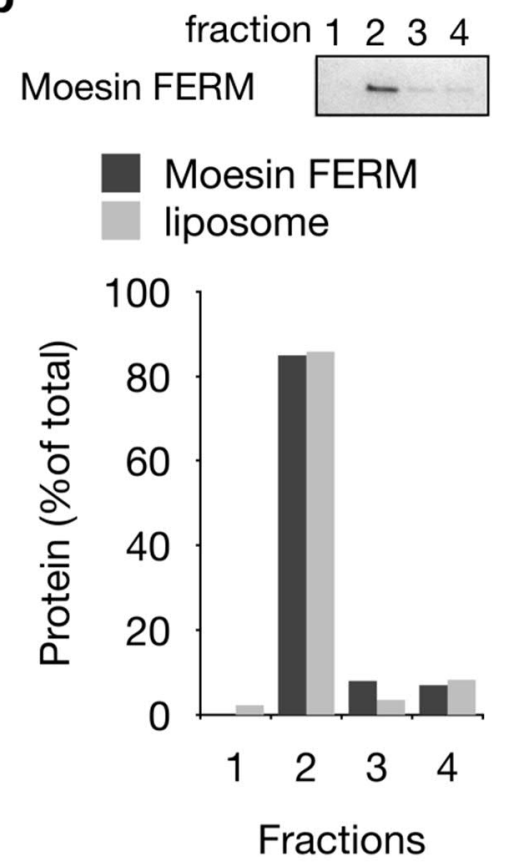

Fig. 2 Liposome co-flotation assay to study protein-phosphoinositide interactions. (a) Schematic representation of a liposome co-flotation assay. Sucrose gradient was generated by ultracentrifugation to separate protein-bound liposomes (fraction 2). During centrifugation, the membrane-associated proteins float with liposomes in a sucrose gradient. (b) Each fraction from the co-flotation assay of Moesin FERM domain was subjected to SDS-PAGE, followed by CBB staining. Fraction 2 contained protein-bound liposomes, which was confirmed by fluorescence spectroscopy [12]. 


\section{References}

1. Roth MG (2004) Phosphoinositides in constitutive membrane traffic. Physiol Rev 84:699-730.

2. Picas L, Gaits-Iacovoni F, Goud B (2016) The emerging role of phosphoinositide clustering in intracellular trafficking and signal transduction. F1000Res:5.

3. Saarikangas J, Zhao H, Pykäläinen A, et al (2009) Molecular mechanisms of membrane deformation by I-BAR domain proteins. Curr Biol 19:95-107.

4. Senju Y, Lappalainen P (2019) Regulation of actin dynamics by PI(4,5)P2 in cell migration and endocytosis. Curr Opin Cell Biol 56:7-13.

5. Rohatgi R, Ho HY, Kirschner MW (2000) Mechanism of N-WASP activation by CDC42 and phosphatidylinositol 4, 5-bisphosphate. J Cell Biol 150:1299-1310.

6. Hamada K, Shimizu T, Matsui T, et al (2000) Structural basis of the membrane-targeting and unmasking mechanisms of the radixin FERM domain. EMBO J 19:4449-4462.

7. Papayannopoulos V, Co C, Prehoda KE, et al (2005) A polybasic motif allows N-WASP to act as a sensor of PIP(2) density. Mol Cell 17:181-191.

8. Zhao H, Michelot A, Koskela EV, et al (2013) Membrane-sculpting BAR domains generate stable lipid microdomains. Cell Rep 4:1213-1223.

9. Prévost C, Zhao H, Manzi J, et al (2015) IRSp53 senses negative membrane curvature and phase separates along membrane tubules. Nat Commun 6:8529.

10. Simunovic M, Manneville J-B, Renard H-F, et al (2017) Friction Mediates Scission of Tubular Membranes Scaffolded by BAR Proteins. Cell 170:172-184.e11.

11. Pykäläinen A, Boczkowska M, Zhao H, et al (2011) Pinkbar is an epithelial-specific BAR domain protein that generates planar membrane structures. Nat Struct Mol Biol 18:902-907.

12. Senju Y, Kalimeri M, Koskela EV, et al (2017) Mechanistic principles underlying regulation of the actin cytoskeleton by phosphoinositides. Proc Natl Acad Sci USA 114:E8977-E8986. 


\section{Acknowledgement}

This work was supported by grants from the Academy of Finland (H.Z., P.L. and Y.S.), Jane and Aatos Erkko Foundation (H.Z.), Guangxi distinguished expert funding (H.Z.), FY2015 Researcher Exchange Program between JSPS and AF (Y.S.), Astellas Foundation For Researcher on Metabolic Disorders (Y.S.), The Scandinavia Japan Sasakawa Foundation (Y.S.), The Ichiro Kanehara Foundation for the Promotion of Medical Sciences and Medical Care (Y.S.) and the Japan Society for the Promotion of Science (Y.S.), The Association for Fordays Self-Reliance Support in Japan (Y.S.), The Futaba Research Grant Program of the Futaba Foundation (Y.S.), The NOVARTIS Foundation (Japan) for the Promotion of Science (Y.S.), Okayama Foundation for Science and Technology (Y.S.), Wesco Scientific Promotion Foundation (Y.S.), and ISPS KAKENHI Grant Numbers JP19K23727, JP20K06589 (Y.S.). 